\title{
NEUROLOGICAL SEQUELAE OF PERTUSSIS WITH PARTICULAR REFERENCE TO MENTAL DEFECT
}

\author{
BY \\ J. M. BERG \\ From the Fountain Hospital, London
}

(RECEIVED FOR PUBLICATION FEBRUARY 25, 1959)

Neurological complications associated with pertussis have long been known. Sears (1929) recorded that Sydenham (1624-1689) noticed that children with whooping cough might have difficulty in walking; cases of paralysis were described by Barrier (1842), Rilliet and Barthez (1843) and Trousseau (1866); and, according to Annell (1953), convulsions in pertussis were first described during epidemics in Copenhagen in 1775 and in Dillingen in 1811.

Many of those with neurological complications die during the acute illness, particularly if affected in the first two years of life, the mortality ranging from $33 \%$ to over $50 \%$ (Miller, 1956). Mortality rates up to $90 \%$ have been reported (Norberg, 1952). Perhaps about half the survivors recover completely, the remainder being left with physical and/or mental sequelae (Litvak, Gibel, Rosenthal and Rosenblatt, 1948; Miller, 1956). Of physical sequelae, epilepsy and paralyses are most frequent. In relation to mental sequelae, figures for complete recovery merit critical appraisal, as there is evidence that various personality and behaviour disturbances later in life are not infrequently related to pertussis in early infancy (Lurie and Levy, 1942; Byers and Rizzo, 1950; Annell, 1953). Without careful psychiatric follow-up, such cases may easily be classed as 'completely recovered' at the end of their acute illness. Frank severe mental retardation following pertussis is less likely to be missed, but has received little attention in the literature, particularly in this country. Such a case is here reported.

\section{Case Report}

No history of mental illness or defect, convulsions or other neurological ailments was elicited from a frank, co-operative mother in any of the following (relationships are to the patient):

Each of the four grandparents died between 69 and 75 years of age. The mother was 34 and the father 40 years old at the child's birth. There is a brother $12 \frac{1}{2}$ years older and a sister two and a half years younger.
The mother has had no miscarriages or stillbirths. On the maternal side, two aunts and four uncles have between them eight children and seven grandchildren; on the paternal side, three aunts and three uncles have 13 children and five grandchildren.

The mother regularly attended an ante-natal clinic during her uneventful pregnancy. The child, a female, was born at full term on November 6, 1955, following an uncomplicated five-hour labour. Birth weight was $6 \mathrm{lb} .14 \mathrm{oz}$. $(3 \cdot 118 \mathrm{~kg}$.). No abnormalities were noted neonatally, and the child thrived from the outset to the complete satisfaction of the parents and a welfare clinic she attended.

Progress was normal, without illness, till 10 months of age. By then, she could combine syllables like 'ma-ma', feed herself with small pieces of food, sit steadily without support, wave goodbye and understand several simple words. She had not been immunized against whooping cough.

Early in September, 1956 (aged 10 months) she developed a 'cold' associated with coughing which soon became paroxysmal and was accompanied by vomiting and an occasional whoop. On September 11 she was admitted to hospital with the diagnosis of whooping cough. On admission her temperature was $100^{\circ} \mathrm{F}$., pulse rate 126 and respiratory rate 26 per minute. She was well-developed, well-nourished and in no acute distress. Apart from this, no abnormal physical signs were found. A post-nasal swab was negative for $H$. pertussis. The white blood count was 19,700 per cubic $\mathrm{mm}$., with $81 \%$ lymphocytes. She was given chloramphenicol, mg. 150 six-hourly for five days.

No untoward developments occurred till September 16, when coughing spasms became more frequent and apnoeic periods replaced the whoop. An hour after the first of these apnoeic periods, the child was staring vacantly into space with all her limbs twitching. This lasted for some 15 minutes. She was not cyanosed and no abnormalities were noted on physical examination. She was sedated with chloral hydrate and put in an oxygen tent for two hours. The child was now placed on achromycin mg. 125 six-hourly for 11 days and phenobarbitone gr. $\frac{1}{4}$ thrice daily.

During the next week at least six such attacks occurred, now associated with cyanosis. On September 25 a particularly severe attack was accompanied by apnoea 
lasting several minutes. She became deeply cyanosed and stuporose, and normal breathing was only restored after 20 minutes of artificial respiration. No further apnoea or cyanosis was observed, though spasmodic coughing continued for 10 more days.

On September 28 she was noted to be drowsy, with twitching of all her limbs. The next day a lumbar puncture yielded a clear cerebrospinal fluid with 60 red cells per cubic mm., no white cells, $40 \mathrm{mg}$. protein per $100 \mathrm{ml}$., globulin not increased and a negative Wassermann reaction. Drowsiness persisted for some days with periodic screaming attacks and convulsive stiffening of the limbs. From October 1 she was given penicillin V mg. 60 six-hourly for 10 days, and, from October 2, intramuscular paraldehyde $\mathrm{ml}$. 1 eight-hourly for four days. Gradually she became less drowsy but continued to be indifferent to her environment. It was then thought that she might be blind, though her fundi were normal. Apart from generalized hypertonicity, there were no other neurological signs.

During the rest of her stay in hospital restlessness, indifference and hypertonic limbs with brisk reflexes were the most notable findings. She had a transient internal strabismus. Clinically, the lungs were normal throughout. Intermittent pyrexia persisted from admission till October 12. No particular pyrexial pattern was associated with the attacks of apnoea, cyanosis and twitching.

The child was discharged on November 16 (aged $12 \frac{1}{2}$ months) in good physical health, but restless and grossly demented. Apart from brisk reflexes, no neurological signs were present. Phenobarbitone, gr. $\frac{1}{4}$ twice daily, was prescribed. The mother described her child on discharge from hospital as 'like a broken doll. She stared all the time, but took no notice of anything'.

In this state she remained at home on phenobarbitone, and without fits, till January, 1957 (aged 14 months), when she was admitted to The Hospital for Sick Children, Great Ormond Street, for further assessment. It was noted that she could not sit unaided and that her behaviour was appropriate to a child of about 6 months. She could see and hear, and no abnormal physical signs, neurological or other, were found. An E.E.G. showed 'generalized abnormality compatible with a diffuse brain disorder'. She was discharged within a week, but readmitted a month later following a series of generalized convulsions associated with cyanosis and frothing at the mouth. Fits continued in hospital for a few days and were eventually controlled by phenobarbitone gr. $\frac{1}{2}$ thrice daily. Again no physical signs were noted and she was discharged.

Till now, December, 1958 (aged $3_{1}^{1 \cdot \overline{2}}$ years), she has remained at home without significant mental progress. She is given phenobarbitone, up to gr. 3 daily, as a prophylactic measure against convulsions which seldom occur unassociated with pyrexial illness. Febrile bouts of upper respiratory infection at $2 \frac{1}{4}$ and $2 \frac{1}{2}$ years of age were associated with convulsions without other neurological signs.

At present (aged $33^{\frac{1}{2}}$ years) she is a well-developed, pretty child with no neurological or other physical signs.

The following psychological report was prepared by
Dr. Mary Woodward: at the age of $3 \frac{1}{1 \cdot 2}$ years, on the Gesell Developmental Schedules, her developmental age was assessed as follows: locomotor scale (12-18 months), prehensory scale (40 weeks), adaptive scale (36-40 weeks), language scale (40 weeks), personal-social scale (44-52 weeks).

She was interested in most of the play material offered to her, though she preferred toys that made a noise.

She shows some unevenness in development. Her method of locomotion (crawling and walking with the aid of furniture) is that of an average year-old baby, whereas her climbing on to a large chair is more advanced behaviour. This is not usually developed until after the child has begun to walk alone. She is reported to take a few steps on her own occasionally, and it is possible that her walking has not developed further because she is timid.

Her language development also has some unusual features. She speaks the names of five people, correctly identifying each, but does not yet use other words denoting objects. She appears as yet to have no verbal comprehension. Personal-social development is also uneven in that she co-operates in dressing, but does not help to hold a cup; the latter response usually occurs much earlier.

Apart from locomotor development, her activities are in general those of the average child of 40 weeks, though her solution of simple problems and her awareness of unperceived objects are slightly in advance of this. She appears at present to be an imbecile.

\section{Discussion}

No example of mental deficiency as a sequel to pertussis has been established in the Fountain Hospital in the last 12 years. This hospital, with an average annual intake of 90 patients, admits children under 6 years, nearly all with I.Q.s below 50 . As an attempt is made to elucidate the cause of the mental retardation in each case, it is unlikely that any substantial number of the total of over 1,000 children who have passed through the hospital in these 12 years owed their defect to whooping cough. However, several authors have indicated that mental defect may follow pertussis more often than is generally thought.

Lurie and Levy (1942) studied a successive group of 500 problem children seen at a child guidance home, 58 of whom had pertussis at or under 2 years of age. Of these 58, six showed progressive intellectual deterioration. Levy and Perry (1948) reported that, among 1,000 successive admissions to a Washington State Institution for children with I.Q.s of 70 or less, there were no fewer than 20 $(2.0 \%)$ in whom 'there appeared to be a definite causal relationship between whooping cough and the intellectual retardation which followed'. Of these 20, eight were classified as idiots, eight as imbeciles and four as low-grade morons. Byers 
and Rizzo (1950) followed up for several years 35 children admitted to the Boston Children's Hospital with whooping cough contracted between 3 weeks old and 2 years. Six of these had intellectual or emotional difficulties which 'seemed sufficiently severe and persistent to compromise their competitive status'. One of the six was a microcephalic idiot and another a mental defective with an I.Q. of 37 , both 'probably due to pertussis'. In view of such reports, it is worth bearing in mind the possible aetiological significance of pertussis in the many cases of mental defect where the causes are obscure.

A variety of neuropathological findings have been reported in cases of pertussis with neurological complications coming to autopsy. Haemorrhagic, inflammatory and degenerative lesions have been described, and many agents and mechanisms postulated to explain them. These include angiospasm, vascular stasis and mechanical damage to cerebral vessels; the action of toxins, viruses or other biological agents; and such factors as air emboli and spasmophilia. These theories. were critically reviewed by Ellison (1934) and more recently by Litvak et al. (1948). In view of the varied pathological findings, it seems likely that all cases are not due to the same cause. With the report of cases in which there was no evidence of cerebral haemorrhage, this formerly much-favoured view of the aetiology lost ground. In recent years, cerebral anoxia, of whatever origin, has been widely regarded as the cause of neurological complications in some cases.

In the present case the association of apnoea with the neurological sequelae is striking. It is tentatively suggested that cerebral anoxia secondary to the apnoea was the basis for the subsequent clinical picture. It is noteworthy that, whatever the cause, it could produce cerebral damage sufficient to lead to imbecility and convulsions, but without paralysis or other persistent focal signs.

\section{Summary}

A case is reported of a normal girl who developed whooping cough at 10 months. During the paroxysmal stage there were frequent periods of apnoea and neurological complications developed, including drowsiness, twitchings of the limbs, hypertonic extremities with brisk reflexes and transient internal strabismus. Screaming attacks and restlessness were also noted. Therapy included chloramphenicol and achromycin. The child survived the acute illness in a grossly demented state and suffering from fits, but without neurological localizing signs. At $3 \frac{1}{12}$ years she was assessed to be of imbecile level. The condition is tentatively attributed to cerebral anoxia consequent on severe apnoea occurring during the paroxysmal stage of pertussis.

Neurological sequelae of pertussis, with particular reference to mental defect, are briefly considered.

My thanks are due to Miss M. F. Craib for drawing my attention to the case and arranging various interviews; to Dr. W. H. Kelleher and Professor A. A. Moncrieff for access to clinical records; to Dr. G. Pampiglione for permission to quote from his E.E.G. report; to Dr. Mary Woodward for her psychological report; to Dr. J. C. McEntee and my colleagues at the Fountain Hospital for helpful suggestions.

\section{REFERENCES}

Annell, A.-L. (1953). Pertussis in Infancy as a Cause of Behaviour Disorders in Children. Acta Soc. Med. upsalien., 58, Supplement I.

Barrier (1842). Cited by Sears (1929).

Byers, R. K. and Rizzo, N. D. (1950). New Engl. J. Med.. 242. 887. Ellison, J. B. (1934). Lancet, 1, 227.

Levy, S. and Perry, H. A. (1948). Amer J. ment. Defic., 52, 217.

Litvak, A. M., Gibel, H., Rosenthal, S. E. and Rosenblatt, P. (1948). J. Pediat., 32, 357 .

Lurie, L. A. and Levy, S. (1942). J. Amer. med. Ass., 120, 890.

Miller, H. (1956). Proc. roy. Soc. Med., 49, 139.

Norberg, A. (1952). Nord. Med., 47, 776.

Rilliet, F. and Barthez, A. (1843). Traité clinique et pratique des Maladies des Enfants, Vol. 2, p. 215. Baillière, Paris.

Sears, W. G. (1929). Brit, J. Child. Dis., 26, 178.

Sydenham, T. (1624-1689). Cited by Sears (1929).

Trousseau (1866). Cited by Sears (1929). 